\title{
An exploratory investigation into the effects of mental defeat on pain threshold, pain rating, pain anticipation, and mood
}

\author{
Victoria E. J. Collard ${ }^{1} \cdot$ Jenna L. Gillett ${ }^{1}$ (D) $\cdot$ Kristy Themelis $^{1}$ (D) $\cdot$ Nicole K. Y. Tang $^{1}$ (D) \\ Accepted: 25 February 2021 / Published online: 10 March 2021 \\ (C) The Author(s) 2021
}

\begin{abstract}
In chronic pain, mental defeat is considered as a disabling type of self-evaluation triggered by repeated episodes of debilitating pain. This exploratory study experimentally tested the effect of an activated sense of defeat, as well as its interaction with pain catastrophizing, on pain and mood. Participants $(N=71)$ were allocated to either high or low pain catastrophizing groups and then randomly assigned to receive either defeat or neutral manipulations. A cold pressor task administered before and after the thought manipulation measured pain threshold, alongside visual analogue scales for mental defeat, attention, pain intensity, pain anticipation as well as mood. Thought manipulation checks supported successful defeat activation. Defeat activation was associated with increased negative mood and attentional disengagement from the nociceptive stimuli, irrespective of pain catastrophizing tendency. There were no changes in pain threshold, pain or pain anticipation ratings. The results suggest that mental defeat can be experimentally activated using an autobiographical memory task and that an activated sense of defeat appears to operate independently from pain catastrophizing in influencing mood and attentional disengagement from the nociceptive stimuli. Future research can utilize our experimental approach to evaluate the effect of an activated sense of mental defeat in people with chronic pain, for whom the magnitude of pain, mood and attentional responses may be stronger and broader.
\end{abstract}

Keywords Mental defeat $\cdot$ Pain $\cdot$ Mood $\cdot$ Attention $\cdot$ Thought manipulation $\cdot$ Pain catastrophizing

Mental defeat is a construct used in a cluster of psychological disorders to explain symptom severity and the development of distress and disability (Taylor, Gooding, Wood, \& Tarrier, 2011). In posttraumatic stress disorder (PTSD), mental defeat is defined as the "perceived loss of autonomy in the face of uncontrollable traumatic events" (Ehlers et al., 1998). Victims of torture and assault who experience a strong sense of defeat are also individuals who display more severe PTSD symptoms and poorer responses to exposure treatment (Dunmore, Clark, \& Ehlers, 2001; Ehlers et al., 1998; Ehlers, Maercker, $\&$ Boos, 2000). In depression, the social rank model of psychopathology proposes depression as a natural response to loss of social status in conflict situations (Price, Sloman, Gardner, Gilbert, \& Rohde, 1994). The perception of defeat in such situations predicts depressive symptoms above and beyond the sense of hopelessness (Gilbert \& Allan, 1998). In the suicide literature, defeat is featured as a key

Nicole K. Y. Tang

n.tang@warwick.ac.uk

1 Department of Psychology, University of Warwick, Coventry, UK cognitive factor driving suicidal thoughts and behavior (O'Connor \& Nock, 2014) in two of the most influential models, the Cry of Pain Model (Williams, 2001) and the Schematic Appraisals Model (Johnson, Gooding, Wood, \& Tarrier, 2010; Williams \& Pollock, 2001).

A central component of mental defeat is the threat to a person's physical and psychological integrity. It has been suggested that the severity of symptoms and perception of defeat can be attributed to both external factors (e.g., trauma, rejection, neglect as a child) and internal factors (e.g., pain, physical illness, emotional/sensory processing), as well as the interplay of these (Gilbert \& Allan, 1998; Pompili et al., 2014; Serafini et al., 2017). Given the high comorbidity between PTSD (Amris \& Williams, 2007; Asmundson, Norton, Allerdings, Norton, \& Larsen, 1998), depression (Buhrman et al., 2015), suicidality (Tang \& Crane, 2006), and chronic pain, mental defeat has been introduced to capture the deeper psychological impact of chronic pain on one's sense of identity and self (Tang, Salkovskis, \& Hanna, 2007). Mental defeat is considered a debilitating type of self-evaluation, whereby frequent occurrences of debilitating pain give rise to negative beliefs about oneself with respect to chronic pain (Tang et al., 2007; Tang, Shum, Leung, Chen, \& Salkovskis, 2013). 
Example thoughts are: "I felt completely at the mercy of what was happening to me", "I felt destroyed as a person", taken from the Pain Self Perception Scale (PSPS) (Tang et al., 2007).

Using the PSPS to measure mental defeat, previous research has shown that mental defeat is higher in patients with chronic pain compared to patients with acute pain, anxiety disorders, community volunteers suffering from acute or chronic pain, and volunteers without significant pain (Tang et al., 2007). Moreover, after controlling for demographics, pain intensity, and mood disturbance, the occurrence of mental defeat distinguished treatment-seeking from non-treatment seeking patients (Tang, Goodchild, Hester, \& Salkovskis, 2010). This corroborates with a recent study showing that $47 \%$ of the variance in patients' reported levels of pain-related self-efficacy is explained by mental defeat, but not the conventional psychological predictors such as anxiety, depression, hopelessness, or pain (Hazeldine-Baker, Salkovskis, Osborn, \& GauntlettGilbert, 2018). Mental defeat may thus be a key cognitive marker of the collapse of pain self-management.

Mental defeat may contribute to the development of distress and disability associated with chronic pain. Previous reviews have established that chronic pain increases suicide risk by up to three times, even after controlling for pain intensity (Fishbain, Lewis, \& Gao, 2014; Tang \& Crane, 2006). Further evidence suggests that mental defeat relates to different dimensions of pain symptoms and that it is functionally distinguishable from existing pain-related psychological constructs (García-Campayo et al., 2010; Tang et al., 2007, 2010).

However, previous studies exploring mental defeat in humans are predominantly cross-sectional in design. A necessary next step is to examine the causal effect on pain responses using experimental methods. Whilst not directly translatable, pre-clinical animal studies have examined links between social defeat and heightened pain responses. Specifically, hyperalgesia has been observed in rodent intruders repeatedly attacked and defeated by an aggressive resident, showing increased escape attempts from nociceptive cold/hot temperatures and elevated proinflammatory cytokine production (Andre et al., 2005; Kinsey, Bailey, Sheridan, Padgett, \& Avitsur, 2007; Marcinkiewcz et al., 2009). These responses were observed in addition to the expected stress responses indicated by demobilized behaviors and elevated cortisol levels (Denmark et al., 2010; Keeney et al., 2006).

The aim of the current study was to evaluate the effect of mental defeat on human pain responses and mood via an experimental design. In particular, whether the sense of mental defeat could be activated experimentally and whether this, when activated, would alter pain ratings. As a proof-ofconcept study, we examined the effect in a healthy, pain-free sample to minimize potential confounds introduced by psychiatric comorbidities and current pain medication use. Given the self-focusing nature of mental defeat (Tang et al., 2007), and the possible interaction with mood and attention, we will investigate attentional focus as possible avenues through which mental defeat impacts on pain rating. Furthermore, to assess whether mental defeat differentially relates to different dimensions of pain symptoms and that it is functionally distinct from pain catastrophizing in predicting distress and disability, participants were split into high or low catastrophizing groups. Based on the reviewed literature, it was hypothesized that mental defeat activation would result in higher defeat ratings taken post-thought manipulation and that those in the defeat activation condition would have a greater increase in defeat compared to the neutral condition (H1). Furthermore, we would expect that an activated sense of mental defeat would have a negative impact on mood (H2) and decrease pain threshold whilst pain ratings and pain anticipation ratings would increase (H3). These effects were not expected in the neutral condition.

\section{Method}

\section{Design}

Figure 1 illustrates the study's design and assessment procedure. A 2 (pain catastrophizing tendency: high vs. low) $\times 2$ (thought manipulation: defeat vs. neutral) $\times 2$ (time: pre- and post-thought manipulation) design was used to examine the effects of pain catastrophizing and defeat on (i)- Pain threshold measurement, (ii)- Attention, (iii)- Pain rating, (iv)- Pain anticipation (v)- Mood, (vi) defeat.

\section{Participants}

Participants were 78 healthy, pain-free volunteers recruited from two university research participant panels. To be eligible for study inclusion, the participants had to be aged 18 years or above and English speaking. Criteria for exclusion included presence or history of: (i) chronic pain, (ii) severe anxiety and/ or depression (as determined by a score of $>15$ on either subscale of the Hospital Anxiety and Depression Scale, in line with recommended cut-off scores for case selection (Bjelland, Dahl, Huag, \& Neckelmann, 2002; Zigmond \& Snaith, 1994), or other major psychological disorders, (iii) frostbite, (iv) open wounds on their hand, and use of pain medication (e.g., paracetamol, ibuprofen, and/or aspirin). Seven of 78 participants screened did not meet the full inclusion/exclusion criteria. Thus, a total of 71 participants were allocated to either high or low pain catastrophizing groups and then randomly assigned to receive either defeat or neutral manipulations. A further 12 were excluded from data analysis because they did not respond to the manipulation in the expected direction as indicated by thought manipulation checks. These excluded participants were in the defeat condition; 3 were high pain catastrophizers and 9 were 
Fig. 1 Study design and assessment procedure flowchart. $(n=x x)$ denotes number of participants included in the final analysis. Pain catastrophizing group (high vs low) was allocated based on median split of baseline PCS score. i) Pain threshold was measured using the Cold Pressor Task. After each pain threshold measurement, participants were asked to rate on a VAS: ii) the extent to which participants were focusing on their hand, thoughts, and surroundings iii) the intensity of experienced pain iv) how much pain they would experience if they were asked to submerge their hand in the water for 3 times longer than they already had, without the option of withdrawal and v) the extent to which they felt joyful, at ease, distressed, or upset. vi) Thought manipulation checks involved VAS ratings in response to six statements asking about participant's feelings. These were administered at the end of Assessment 1 and the beginning of Assessment 2 to capture changes in defeat postthought manipulation. Individual measures within each round of assessment are presented in chronological order. *Thought manipulation reversal was only applicable to participants who were assigned to receive the defeat thought manipulation

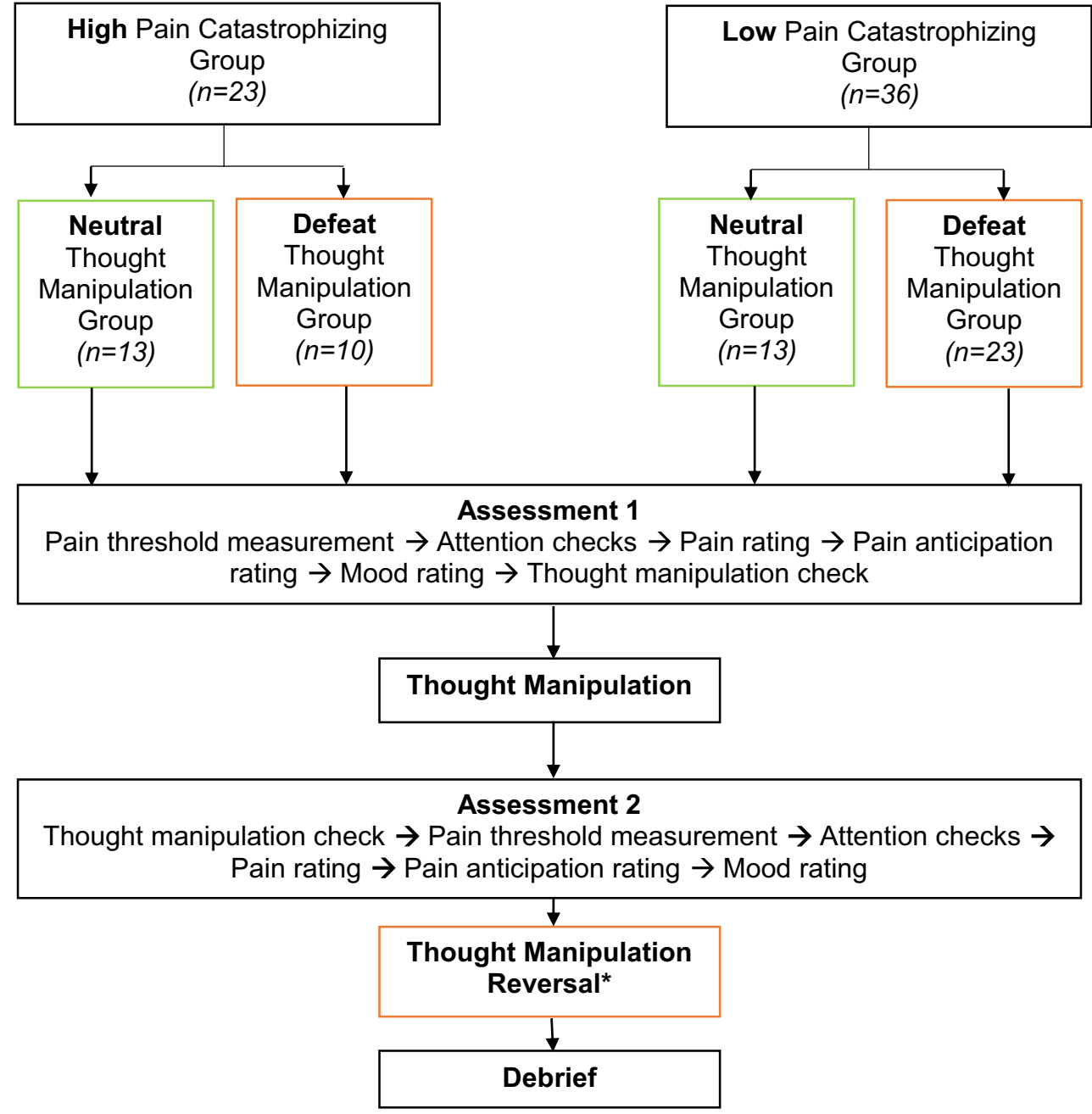

low pain catastrophizers. The final sample thus comprised 59 participants.

\section{Measures}

Assessment Questionnaire This was used to obtain demographic information about participants' age, sex, ethnicity, employment status, highest education level, relationship status, and Body Mass Index (BMI). For screening and sample characterization, the assessment questionnaire included the Brief Pain Inventory's present pain intensity rating (Cleeland \& Ryan, 1994) and the Hospital Anxiety and Depression Scale (Zigmond \& Snaith, 1983) to measure current presence of pain and symptoms of anxiety and depression.

Pain Catastrophizing Scale (PCS) A 13-item scale measuring catastrophic thinking related to past experiences (Sullivan, Bishop, \& Pivik, 1995). Responses were rated on a 5-point Likert scale $(0=$ not at all to $4=$ all the time $)$ with a total score ranging from 0 to 52 . The PCS has good overall internal reliability, $\alpha=.92$ (Wheeler, Williams, \& Morley, 2019). In the absence of an established cut-off for non-clinical populations, a median split score of 18.3 was used for pain catastrophizing group assignment (high pain catastrophizing $\geq 18.3$; low pain catastrophizing $<18.3$ ). Using the median split is deemed an appropriate method for categorizing high and low catastrophizing in non-clinical samples (Sullivan et al., 1995; Van Damme, Crombez, \& Eccleston, 2004) with similar median split scores recognized in pain-free samples e.g. Sullivan, Adams, and Sullivan (2004) and Van Damme et al. (2004).

Attention Checks Immediately after each cold pressor task (CPT), participants were asked to indicate on three separate $100 \mathrm{~mm}$ VAS the extent to which they were focusing on (i) their immersed hand, (ii) their own thoughts, and (iii) their surroundings. Each VAS had "not at all" as the left anchor (scored 0) and "very much so" as the right anchor (scored 100).

Thought Manipulation Checks Six "I feel..." statements prefixed"...defeated", “...powerless", “...humiliated”, “... 
indifferent", “...impartial", and "...neutral" were administered immediately pre- and post-thought manipulation. Answers for each were indicated on corresponding $100 \mathrm{~mm}$ VAS, with "low" as the left anchor (scored 0) and "high" as the right anchor (scored 100). The "...defeated" item ratings were used to determine manipulation success. For inclusion in final data analysis, ratings from the defeat condition needed to demonstrate a minimum increase of at least 10 points on the "...defeated" VAS. Ratings from the neutral condition needed to not have an increase/decrease of greater than 5 points on the "...defeated" VAS.

\section{Primary Outcome Measures}

Pain Threshold Measurement A Cold Pressor Task (CPT) was used to assess cold pain threshold pre- and post-thought manipulation. This involved the use of an 18-litre circulating chilled water bath (model T100; Grant Instruments Cambridge Ltd.) with water temperature maintained at $4{ }^{\circ} \mathrm{C}$ (von Baeyer, Piira, Chambers, Trapanotto, \& Zeltzer, 2005). Participants were asked to submerge their hand and wrist in the water until the instance when they defined the sensation they were feeling to be 'pain'. The recorded duration from hand immersion to withdrawal from the water provided an index of pain threshold (Loeser \& Treede, 2008).

Pain Rating After each CPT, participants were asked how much pain they experienced when their hand was submerged. A $100 \mathrm{~mm}$ VAS indicated their pain rating with "not painful at all" as the left anchor (scored 0) and "worst pain felt" as the right anchor (scored 100).

Pain Anticipation Rating After each pain rating, participants were asked to estimate how much pain they would experience, if "for the final task of the session, they were asked to submerge their hand in the water for 3 times longer than they already had, without the option of withdrawal". Answers were indicated on a $100 \mathrm{~mm}$ VAS with "no pain" as the left anchor (scored 0) and "worst pain imaginable" as the right anchor (scored 100).

\section{Secondary Outcome Measures}

\section{Mood Ratings}

State measures of positive and negative mood were taken immediately before and after each CPT. Four mood statements were used; two to assess positive mood ("I feel joyful", "I feel at ease") and two to assess negative mood ("I feel distressed" and "I feel upset"). Mood descriptors were chosen from Positive and Negative Affects Schedule items (Watson, Clark, \& Tellegen, 1988). Participants were asked to indicate the extent to which they felt these emotions on a
100 mm VAS, with "low" as the left anchor (scored 0) and "high" as the right anchor (scored 100). Averages of these pairs were taken as the positive and negative mood ratings.

\section{Procedure}

Prior to the test session, participants were asked to complete the PCS and a written task comprising three paragraphs detailing specific past autobiographical memories: (a) a typical day-to-day experience at home/work/university, (b) an experience that directly affected them, by making them feel defeated at the time, and (c) an experience that directly affected them, by making them feel victorious at the time. Then they completed a baseline set of measurements; Pain threshold measurement including the CPT (timed using a stopwatch), attention checks, pain rating, pain anticipation rating, mood ratings and the first set of thought manipulation checks. The thought manipulation took place in a quiet room with no distraction for three minutes. The participants were asked to sit in a comfortable position, close their eyes and concentrate on their thoughts. Those in the defeat group were presented with their written paragraph about a past experience which left them feeling defeated. Those in the neutral group underwent the same procedure but using their neutral paragraph. In both conditions, they were asked to try to relive their written experience, based on previously established mood induction methods (Baas, De Dreu, \& Nijstad, 2008). Participants were asked to channel all feelings associated with that experience back to the present. They were told to try and feel the full extent of their experience without filtering any associated emotions. Participants were left alone to relive this. Afterwards, they were asked to provide a second set of thought manipulation checks. A second round of pain measurements followed to index change associated with the thought manipulation. Finally, participants in the defeat group were given an additional victory thought manipulation, using their victory paragraph, to neutralize any effects of the defeat manipulation.

\section{Data Analysis}

Missing data were deleted listwise (McNeish, 2017). Preliminary data screening revealed that the cold pain threshold and negative mood data displayed excessive kurtosis thus values were square-root transformed before further analysis. Differences in demographic variables between the two groups were analyzed with ANOVAs (mean and SD). Differences in sex and ethnicity were analyzed using a chi-square test. Between group differences in the demographic variables (pain catastrophizing; high vs low, thought manipulation group; defeat vs neutral) were indicated by independent samples t-tests $(t, 95 \% \mathrm{CI})$. For the main analysis, a 3-way ANOVA was used with the variables "pain catastrophizing", "thought 
manipulation", and "time". Post-hoc comparisons between groups or over time were conducted to follow-up on any significant interaction or main-effect. Partial eta squared $\left(\eta p^{2}\right)$ values were reported as an indicator of effect size, a value of 0.01 is considered small, 0.06 medium and 0.14 or above large (Cohen, 1992). Finally, two-tailed intercorrelations between changes in the variables were also calculated using Pearson's $\mathrm{r}$, of which a value of $>.5$ is considered a large/strong correlation (Cohen, 1988). Change scores were calculated by subtracting each outcome measure's pre-thought manipulation value from each of their post-thought manipulation values to index the difference for each variable.

\section{Results}

\section{Participant Characteristics}

Table 1 presents the participant characteristics. No significant differences between manipulation groups (defeat or neutral) were found for sex, BMI, BPI, anxiety or depression but there was a significant difference in pain catastrophizing score at baseline. Additionally, no significant differences in pain catastrophizing groups (high or low) were found for age, but as expected, significant differences between catastrophizing groups were detected for sex, BMI, BPI anxiety, depression and pain catastrophizing score. Differences in ethnicity could not be evaluated due to not passing the minimum sample size requirements in each subcategory.

\section{Manipulation Checks and Outcome Measures}

Table 2 presents a summary of the analysis, showing the pattern of significant interaction and main effects across measures. There were no significant 3-way interactions (pain catastrophizing tendency $\mathrm{x}$ thought manipulation $\mathrm{x}$ time) observed for any of the manipulation checks or outcome measures. Moreover, there were no significant 2-way pain catastrophizing tendency $\mathrm{x}$ thought manipulation

Table 1 Participant characteristics for each group at baseline

\begin{tabular}{|c|c|c|c|c|c|c|c|c|c|}
\hline \multirow[b]{3}{*}{ Measure } & \multicolumn{3}{|c|}{$\begin{array}{l}\text { High pain } \\
\text { catastrophizing (HPC) } \\
(n=23)\end{array}$} & \multicolumn{2}{|c|}{$\begin{array}{l}\text { Low pain } \\
\text { catastrophizing (LPC) } \\
(n=36)\end{array}$} & \multicolumn{4}{|c|}{ Group differences } \\
\hline & \multirow{2}{*}{$\begin{array}{l}\text { Overall } \\
(n=59)\end{array}$} & \multirow{2}{*}{$\begin{array}{l}\text { Defeat (D) } \\
(n=13)\end{array}$} & \multirow{2}{*}{$\begin{array}{l}\text { Neutral }(\mathrm{N}) \\
(n=10)\end{array}$} & \multirow{2}{*}{$\begin{array}{l}\text { Defeat (D) } \\
(n=13)\end{array}$} & \multirow{2}{*}{$\begin{array}{l}\text { Neutral }(N) \\
(n=23)\end{array}$} & \multicolumn{2}{|c|}{ HPC vs LPC } & \multicolumn{2}{|l|}{ D vs N } \\
\hline & & & & & & $\operatorname{tor} \chi^{2}$ & $95 \% \mathrm{CI}$ & tor $\chi^{2}$ & $95 \% \mathrm{CI}$ \\
\hline Age (y) & $27.3(8.5)$ & $24.5(7.9)$ & $28(9.2)$ & $30.5(10.3)$ & $26.8(7.4)$ & -.9 & -6.7 to 2.5 & -.1 & -4.8 to 4.2 \\
\hline $\operatorname{Sex}(n, \%)$ & & & & & & $6.3^{*}$ & & 1.4 & \\
\hline Female & $29(49.2)$ & $9(69.2)$ & $7(70)$ & $6(46.2)$ & $7(30.4)$ & & & & \\
\hline Male & $30(50.8)$ & $4(30.8)$ & $3(30)$ & $7(53.8)$ & $16(69.6)$ & & & & \\
\hline \multicolumn{10}{|l|}{ Ethnicity $(n, \%)$} \\
\hline White & $21(35.6)$ & $3(23.1)$ & $3(30)$ & $6(46.2)$ & $9(39.1)$ & & & & \\
\hline Black & $5(8.5)$ & $3(23.1)$ & $0(0)$ & $1(7.7)$ & $1(4.3)$ & & & & \\
\hline Asian & $19(32.2)$ & $5(38.5)$ & $5(50)$ & $3(23.1)$ & $6(26.1)$ & & & & \\
\hline Chinese & $10(16.9)$ & $2(15.4)$ & $2(20)$ & $2(15.4)$ & $4(17.4)$ & & & & \\
\hline Mixed & $4(6.8)$ & $0(0)$ & $0(0)$ & $1(7.7)$ & $3(13)$ & & & & \\
\hline $\mathrm{BMI}\left(\mathrm{kg} / \mathrm{m}^{2}, \mathrm{SD}\right)$ & $23.2(3.4)$ & $21.3(3.3)$ & $22.4(3.8)$ & $23.5(3.8)$ & $24.4(2.5)$ & $-2.6^{*}$ & -4.1 to -.6 & 1.6 & -.4 to 3.2 \\
\hline Brief Pain Inventory (BPI) & $1.4(2.2)$ & $0.5(0.9)$ & $0.7(1.1)$ & $1.4(2.5)$ & $2(2.6)$ & $-2.6^{*}$ & -2.2 to -.3 & 1.2 & -.5 to 1.8 \\
\hline Anxiety (HADS) & $6.2(3.3)$ & $8.6(3.8)$ & $7.1(2.5)$ & $4.4(3.4)$ & $5.4(2.5)$ & $3.7 * *$ & 1.4 to 4.6 & -.7 & -2.5 to 1.2 \\
\hline Depression (HADS) & $3.2(2.8)$ & $4.2(3.9)$ & $4.8(3.2)$ & $2(1.5)$ & $2.6(2.1)$ & $2.6^{*}$ & .4 to 3.7 & .3 & -1.3 to 1.7 \\
\hline Pain Catastrophizing Scale (PCS) & $15.5(9.4)$ & $25.6(8.4)$ & $23.3(5.3)$ & $11.5(4.8)$ & $8.52(4.7)$ & $9.6 * * *$ & 11.9 to 18.1 & $-2.4 *$ & -10.3 to -.8 \\
\hline
\end{tabular}

Statistical significance of each t-test is indicated by $* * * p<.001 ; * * p<.01 ; * p<.05$

Means and SDs, and, where relevant, frequency and percentage $(\%)$ of the total sample $(\mathrm{n}=59)$ are reported. $t$ values are reported for independent samples t-tests except for sex where chi-square tests of independence $\left(\chi^{2}\right)$ were used. Ethnicity violated the statistical assumptions of chi-square tests so was not analysed. 95\% CI = 95\% confidence interval of the difference; $n$ number of participants, HPC High Pain Catastrophizing group, $L P C$ Low Pain Catastrophizing group, $D$ Defeat manipulation group, $N$ Neutral manipulation group, BMI Body Mass Index, BPI Brief Pain Inventory, HADS Hospital Anxiety and Depression Scale, PCS Pain Catastrophizing Scale 
Table 2 Summary of $2 \times 2 \times 2$ Mixed ANOVAs: main effects and interactions by outcome measure

\begin{tabular}{|c|c|c|c|c|c|c|c|c|}
\hline & & \multicolumn{3}{|l|}{$\begin{array}{l}\text { Main Effects } \\
F, p \text { value }\end{array}$} & \multicolumn{3}{|c|}{$\begin{array}{l}\text { Two-Way Interactions } \\
F, p \text { value }\end{array}$} & \multirow{2}{*}{$\begin{array}{l}\text { Three-Way Interaction } \\
F, p \text { value } \\
T^{*} T M^{*} P C S\end{array}$} \\
\hline & & $T$ & $T M$ & $P C S$ & $T * T M$ & $T * P C S$ & $T M * P C S$ & \\
\hline \multirow[t]{3}{*}{ Attention checks } & Hands & $4.23, .04$ & $.11, .73$ & $.99, .32$ & $.30, .59$ & $.64, .43$ & $.03, .85$ & $.28, .60$ \\
\hline & Thoughts & $26.39, .00$ & $.35, .56$ & $.54,47$ & $5.60, .02$ & $.71, .40$ & $.56, .46$ & $1.36, .25$ \\
\hline & Surroundings & $.001, .98$ & $4.52, .04$ & $.12 . .73$ & $.00, .99$ & $2.32, .13$ & $2.14, .15$ & $.25, .62$ \\
\hline Manipulation check & Defeat & $72.72, .00$ & $17.14, .00$ & $4.21, .05$ & $134.82, .00$ & $1.77, .19$ & $.28, .60$ & $3.87, .06$ \\
\hline \multirow{3}{*}{$\begin{array}{l}\text { Primary } \\
\text { outcomes }\end{array}$} & Cold Pain Threshold & $.42, .52$ & $.002, .96$ & $.35, .60$ & $2.14, .15$ & $.55, .46$ & $.70, .41$ & $.79, .38$ \\
\hline & Pain Rating & $7.14, .01$ & $3.54, .06$ & $3.43, .07$ & $3.37, .06$ & $.33, .57$ & $.14, .71$ & $.55, .46$ \\
\hline & Pain Anticipation & $.46, .50$ & $1.47, .23$ & $.50, .48$ & $3.83, .06$ & $.55, .46$ & $1.21, .28$ & $.43,52$ \\
\hline \multirow[t]{2}{*}{ Secondary outcomes } & Positive Mood & $12.47, .001$ & $3.96, .05$ & $3.39, .07$ & $1.69, .20$ & $1.98, .17$ & $.52,47$ & $.001, .98$ \\
\hline & Negative Mood & $25.22, .00$ & $21.33, .00$ & $4.22, .04$ & $24.41, .00$ & $6.75, .01$ & $1.94, .17$ & $3.08, .09$ \\
\hline
\end{tabular}

Significant main effects and interactions are in bold type. $T$ "Time" (pre and post), TM "Thought Manipulation" (defeat vs neutral), PCS Pain Catastrophising (high vs low)

interactions observed for any of the manipulation checks or outcome measures.

\section{Attention Checks}

For the attention to hand rating (Fig. 2a), there were no significant 2-way interactions. Only a main effect of time was found $\left(F(1,55)=4.23, p=.04, \eta p^{2}=.07\right)$, indicating that participants across thought manipulation and pain catastrophizing groups paid less attention to their hand during the second pain threshold measurement $(M=56.93,95 \% C I[49.93,63.93])$, compared with the first $(M=65.58,95 \% C I[58.09,73.08])$ $(p<.05)$.

For the attention to thoughts rating (Fig. 2b), there was a significant 2-way interaction between time and thought manipulation, $F(1,55)=5.60, p=.02, \eta \mathrm{p}^{2}=.09$ only. However, post-hoc comparisons indicated no significant differences in attention to thoughts rating between the mental defeat and neutral groups at pre- or post-thought manipulation. There was a significant effect of time $F(1,55)=26.39, p<.001$, $\eta \mathrm{p}^{2}=.32$, with participants across groups paying more attention to one's own thoughts post-thought manipulation $(M=$ $47.59,95 \% C I[49.72,65.46])$ compared with pre-thought manipulation $(\mathrm{M}=34.5,95 \% C I[26.56,42.43])(p<.001)$.

For the attention to surroundings rating (Fig. 2c), there were no significant 2 -way interactions. There was only a main effect of thought manipulation group $(F(1,55)=4.52, p=.04$, $\left.\eta \mathrm{p}^{2}=.08\right)$, whereby participants in the defeat group paid generally more attention to their surroundings $(M=30.85,95 \%$ $C I[22.6,39.09])$ as opposed to the neutral group $(M=18.68$, $95 \% C I[10.7,26.64])(p<.05)$.

\section{Thought Manipulation Checks}

There was a significant 2-way interaction between time and thought manipulation observed $F(1,55)=134.82, p<.001$, $\eta p^{2}=.71$ (Fig. 3a). There was a main effect of time $F(1,55)=72.72, p<.001, \eta p^{2}=.6$, and thought manipulation

\section{a}

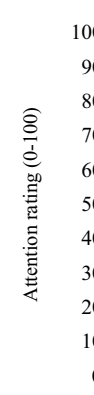

b

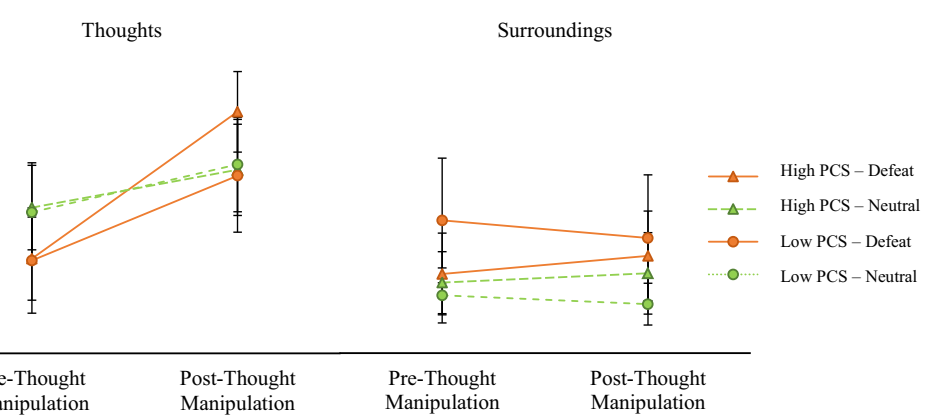

Fig. 2 Effect of thought manipulation (defeat vs neutral) on attention ratings for (a) hand, (b) thoughts and (c) surroundings grouped by pain catastrophizing tendency (high vs low). Error bars represent $1 \pm$ actual standard error of the mean estimated from reported data. a Mean attention ratings for hand. $\mathbf{b}$ Mean attention ratings for thoughts. $\mathbf{c}$ Mean attention ratings for surroundings 

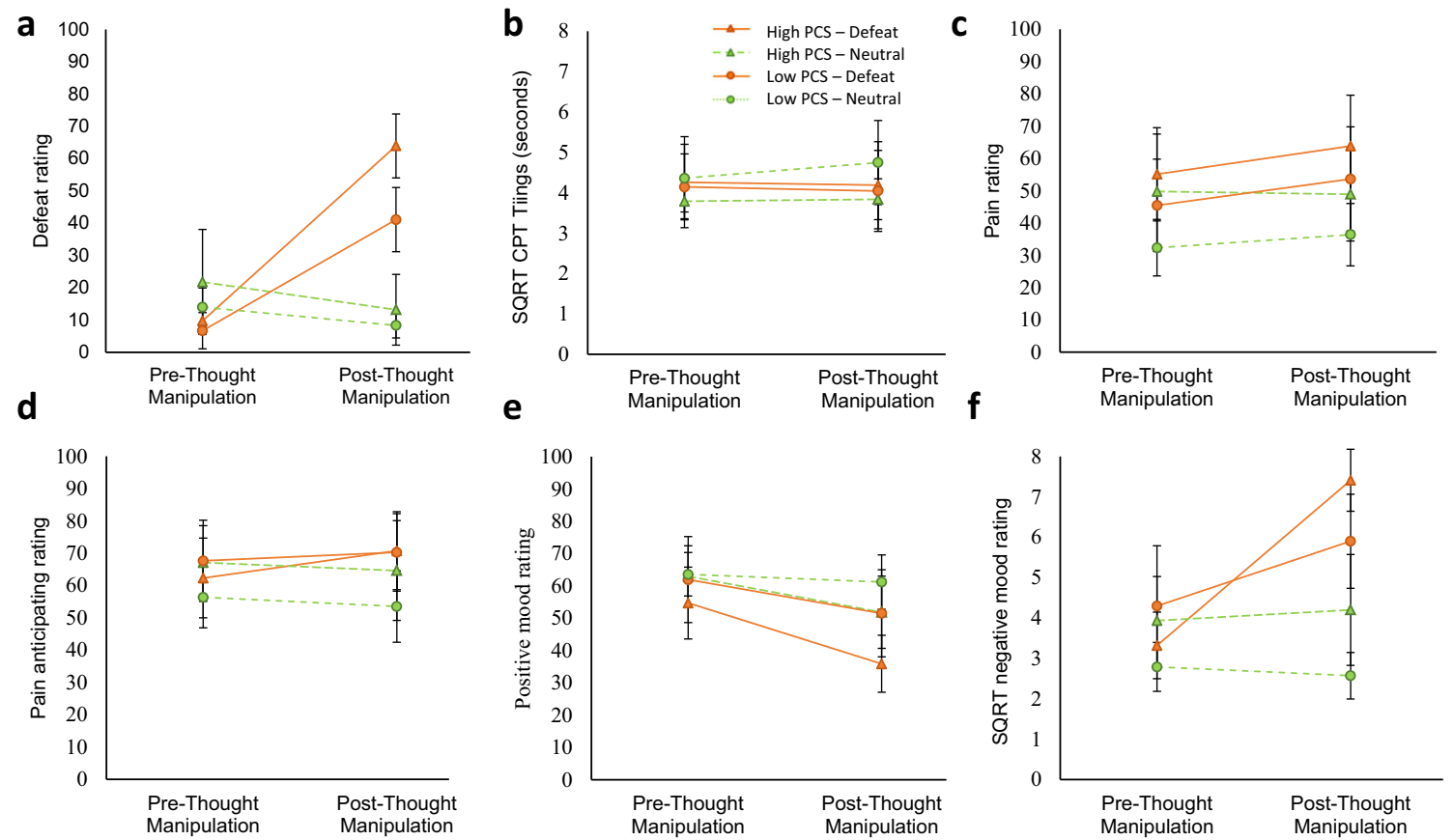

Fig. 3 Effect of thought manipulation (defeat vs neutral) on defeat, pain threshold, pain rating, pain anticipation, and mood ratings (positive and negative) grouped by pain catastrophizing tendency (high vs low). Error bars represent $1 \pm$ actual standard error of the mean estimated from

reported data. a Mean defeat ratings $\mathbf{b}$ Mean of square-root transformed cold pressor task (CPT) ratings $\mathbf{c}$ Mean pain ratings d Mean pain anticipation ratings e Mean positive mood ratings $\mathbf{f}$ Mean of square-root transformed negative mood ratings

$F(1,55)=17.14, p<.001, \eta p^{2}=.3$. The two groups did not differ significantly in their defeat ratings pre-thought manipulation, but as expected, the defeat rating was higher in the defeat group $(M=54.77,95 \% C I[47.18,62.36])$ than the neutral group $(M=10.77,95 \% C I[3.45,18.10])$ postthought manipulation $(p<.001)$. Paired sample t-tests testing for changes in defeat ratings between assessments for each thought-manipulation group indicated that the defeat group had an increase $(M D=16.85,95 \% C I[8.58,25.11])$ $(p<.001)$, whereas the neutral group had a decrease in defeat ratings at post-thought manipulation $(M D=-3.10,95 \% C I$ $[-10.36,4.15])(p=.40)$.

\section{Cold Pain Threshold}

In addition to no significant 3-way interactions, there were no significant 2-way interactions nor any significant main effects found for CPT (Fig. 3b).

\section{Pain Rating}

Only a main effect of time was found $F(1,55)=7.14$, $p=.01, \eta \mathrm{p}^{2}=.12$, indicating that participants across groups had higher pain ratings post-thought manipulation $(\mathrm{M}=50.69,95 \%$ CI $[43.53,57.85])$ compared with prethought manipulation $(\mathrm{M}=45.67,95 \% C I[38.85,52.49])$ $(p<.01)$ (Fig. 3c).

\section{Pain Anticipation Rating}

In addition to no significant 3-way interactions there were no significant 2-way interactions nor any significant main effects observed for pain anticipation rating (Fig. 3d).

\section{Mood Ratings}

For positive mood ratings (Fig. 3e), there were no significant 2-way interactions. A main effect of time was found $\left(\mathrm{F}(1,55)=12.47, p=.001, \eta \mathrm{p}^{2}=.19\right)$, whereby participants across groups gave lower positive mood ratings post-thought manipulation $(\mathrm{M}=50.11,95 \% C I[44.54,55.67])$ than prethought manipulation $(\mathrm{M}=60.80,95 \% C I[55.56,66.05])$ $(p<.01)$.

For negative mood ratings (Fig. 3f), there was a significant 2-way interaction between time and thought manipulation $F(1,55)=24.41, p<.001, \eta \mathrm{p}^{2}=.31$. Whilst the two groups did not significantly differ in their ratings at pre-thought manipulation, the defeat group $(M=3.81$, 95\% CI $[3.07,4.55])$ had higher negative mood ratings than the neutral group $(M=3.36,95 \% C I[2.65,4.07])$ $(p<.001)$. There was a similar pattern for the interaction between time and pain catastrophizing tendency $F(1$, $55)=6.75, p=.01, \eta p^{2}=.12$, with significant differences in negative mood ratings between catastrophizing groups post-thought manipulation (high: $M=5.80,95 \% C I[5.07$, 
6.54]; low: $M=4.23,95 \% C I[3.63,4.84])(p<.01)$ but not at pre-thought manipulation. There were also significant main effects of time $F(1,55)=25.22, p<.001$, $\eta \mathrm{p}^{2}=.31$, thought manipulation $F(1,55)=21.33, p$ $<.001, \eta \mathrm{p}^{2}=.28$ and catastrophizing tendency $F(1$, $55)=4.22, p=.04, \eta p 2=.07$. Overall, negative mood ratings were higher post-thought manipulation $(M=5.02$, $95 \% C I[4.54,5.49])$, relative to pre-thought manipulation $(M=3.58,95 \% C I[3.07,4.10])(p<.01)$, in the defeat group $(M=5.23,95 \% C I[4.65,5.81])$ relative to the neutral group $(M=3.37,95 \% C I[2.81,3.93])(p<.001)$, and amongst high catastrophizers $(M=4.72,95 \% C I$ [4.09, 5.34]) relative to low catastrophizers $(M=3.89,95 \% C I$ $[3.37,4.40])(p<.01)$.

\section{Correlational Analyses}

Pearson's correlations (r) between changes in defeat, attention, pain threshold, pain, pain anticipation and mood ratings pre-post thought manipulation are presented in Fig. 4. As can be seen, an increase in defeat rating was found to be significantly correlated with an increase in pain anticipation, negative mood, attention to thoughts, as well as a decrease in positive mood. An increase in pain rating was significantly correlated with an increase in attention to thoughts, which negatively correlated with attention to hand. An increase in pain anticipation was significantly correlated with an increase in both attention to thoughts and defeat ratings. Increases in pain rating and pain anticipation, in turn, were correlated with each other, whilst reductions in cold pain threshold were significantly correlated with increases in attention to surroundings.

\section{Discussion}

\section{Summary of Main Findings}

The current study was the first to experimentally evaluate mental defeat's effect on pain responses, representing a stepchange from the predominantly cross-sectional and correlational mental defeat literature (Fishbain et al., 2014; GarcíaCampayo et al., 2010; Hazeldine-Baker et al., 2018; Tang et al., 2007; Tang et al., 2010, 2013; Tang \& Crane, 2006). Findings show that mental defeat can be successfully activated using a personally tailored autobiographical memory task, the results of which post-thought manipulation were independent of pain catastrophizing. Subsequent increase in negative - and decrease in positive - mood ratings suggest mood as a tenable pathway through which mental defeat may operate. Reflecting the well-established interrelationship between mood, attention and pain, findings of this proof-of-concept also highlight the importance of exploring attentional mechanisms in the experience of pain.

\section{Mental Defeat Activation through Mood}

Consistent with our first hypothesis, mental defeat activation resulted in higher defeat ratings post-thought manipulation compared to pre-thought manipulation in the majority $(75 \%)$ of pain-free participants randomly assigned to the defeat group. In contrast, the neutral autobiographical memory task significantly reduced defeat ratings in the neutral group. The mean increase in defeat rating did not differ between participants with high or low pain catastrophizing tendency; inferring independent cognitions are implicated in the manifestation of mental defeat.
Fig. 4 Pearson's correlation matrix of change scores with annotated heatmaps

$(n=59)$. Statistical significance of each bivariate (two-tailed) correlation analyses is presented $* * *$ $p<.001 ; * * p<.01 ; * p<.05$. Change of each variable was calculated by subtracting each outcome measure's pre-thought manipulation value from each of their post-thought manipulation values to index the difference for each variable

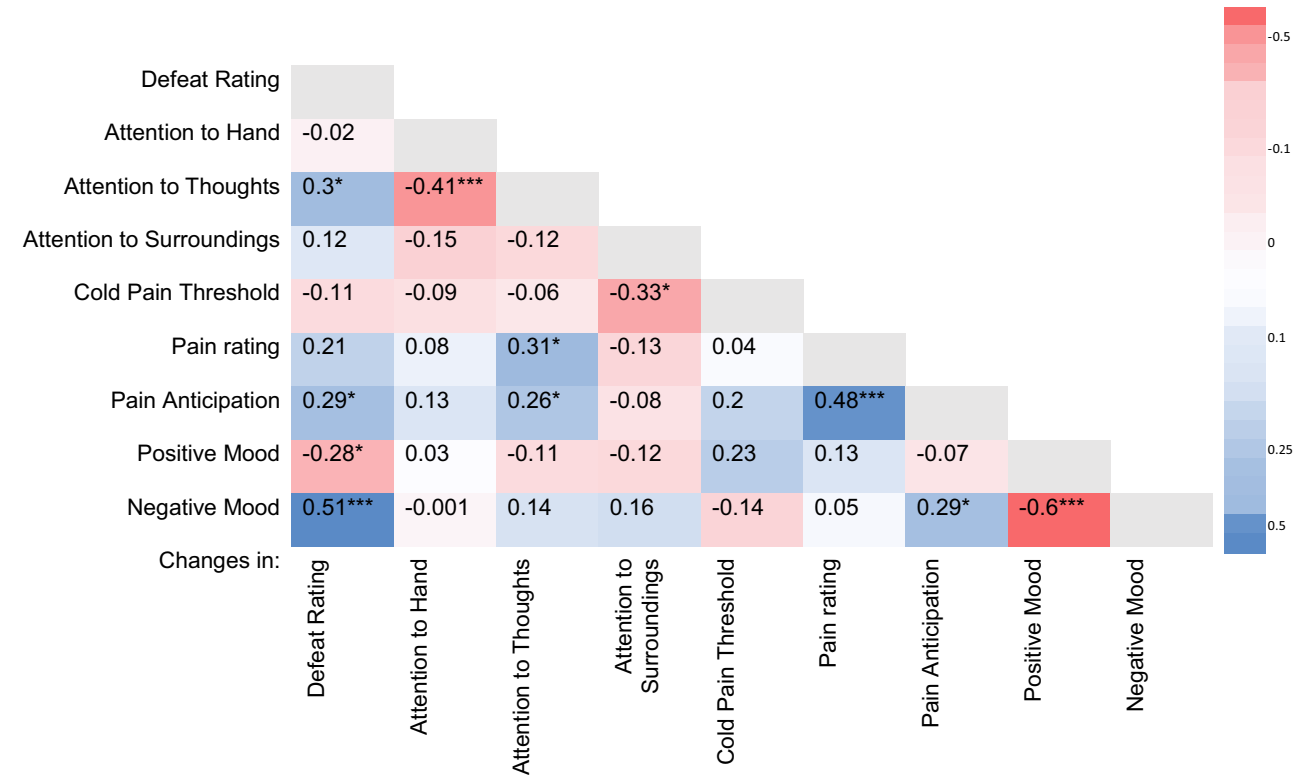


In line with our second hypothesis, activating mental defeat also had a profound effect on mood. Participants in the defeat condition reported an increase in negative mood and both groups had a decrease in positive mood following the thought manipulation. The effect was more robust for negative than positive mood, which is not unexpected given that the defeat thought manipulation specifically instructed the participants to recall and relive a significant memory of personal defeat. Reliving a defeating memory is naturally upsetting; it is a common method shared by established mood induction procedures that aims to temporarily activate such states for testing purposes (Carnes et al., 2013; Martin, 1990). There is a substantial body of research on the reciprocal link between depression and pain, with pain being a significant physical and psychological stressor that worsens mood and causes depressive symptoms. Low mood, in turn, intensifies the pain experience and aggravates depressive thinking and behavior that render daily pain management difficult (Arnow et al., 2006; Bair, Robinson, Katon, \& Kroenke, 2003; Banks \& Kerns, 1996; Blackburn-Munro, 2004; Brown, 1990; Fishbain, Cutler, Rosomoff, \& Rosomoff, 1997; Romano \& Turner, 1985; Von Korff \& Simon, 1996). Resultant mood changes from our thought manipulation procedure highlight this close connection between cognition and emotion.

The current study used healthy, pain-free adults to evaluate the isolated effect of mental defeat using a safe, well-validated CPT showing effects on defeat ratings and mood. It is likely that for patients with chronic pain, who generally show elevated levels of mental defeat (Tang et al., 2007), the tailored autobiographical memory task asking about defeat would bear greater relevance and would exert a stronger effect on these outcome measures. This raises implications for future research aiming to use an autobiographical memory task as effective means to induce mental defeat in patients with chronic pain and assess its effects on health status.

\section{Roles of Attention and Catastrophizing in Experimental Pain}

There were measurable changes in the participants' attention following thought manipulation. The findings highlight a possible attentional avenue through which mental defeat impacts on pain rating. During the CPT, both thought manipulation groups were associated with an overall decrease in attention to hands (where the noxious stimulus was applied) post-thought manipulation. This was accompanied by a significant increase in attention to one's own thoughts for both groups. It is possible that participants inferred pain based on their feelings/ thoughts instead of the actual experience in their hand. In general, the defeat group paid more attention to their surroundings compared to the neutral group. It is known that shifting attention away from the nociceptive stimuli, may result in pain reduction (Legrain et al., 2009). These results suggest that participants might have been using attentional disengagement from the stimulus site to one's own thoughts and surroundings as a possible coping strategy during the CPT.

The overall pattern of results on pain outcome measures contrasted our third hypothesis that activating a sense of mental defeat would alter pain responses, as previously observed in mice studies using social defeat models (Andre et al., 2005; Kinsey et al., 2007; Marcinkiewcz et al., 2009). An increase in defeat rating did correlate with an increase in pain anticipation, but not with an increase in pain rating or a decrease in pain threshold. However, we cannot discount the possibility that mental defeat could have a significant impact on pain responses if a larger, clinical sample of patients with chronic pain were tested instead. Indeed, the main effect of defeat $(p=.06)$ and time*thought manipulation interaction $(p=.06)$ for pain rating, as well as time*thought manipulation for pain anticipation rating $(p=.06)$ approached significance at the $p<.05$ level in this study. Previous experimental work has demonstrated that patients with chronic pain exhibit increased attentional biases towards pain-related stimuli, enhanced selective pain-related memory in self-referent conditions, and autobiographical memory bias towards retrieving memories incorporating elements of physical pain about the self (Pincus \& Morley, 2001). Thus, a personally tailored autobiographical memory task could elicit a stronger sense of mental defeat, and hence heightened pain responses, in patients who have directly relevant defeating experiences compared to pain-free controls, whose null findings in pain variables may be due to a floor effect.

Whilst participants' tendency to catastrophize about pain accounted for some of the baseline differences seen in BMI, BPI, anxiety, depression and pain catastrophizing levels across groups, other effects were limited to a medium effect on negative mood reports, with no significant effect on any of the pain outcome measures. These findings are similar to previous literature which postulates that catastrophizing tendency can impact mental health parameters (Linton et al., 2011) as well as self-reported levels of pain, wherein high catastrophizers tend to demonstrate a propensity for salience of pain (Galambos et al., 2019), but the results of this study demonstrate that these effects occur independent of mental defeat. Pain catastrophizing is a psychological construct that is well established in the field of chronic pain and is a prominent component of the fear avoidance model that seeks to understand the persistence of chronic pain and the associated development of disuse, depression and disability (Sullivan et al., 1995; Sullivan et al., 2001; Vlaeyen, Kole-Snijders, Boeren, \& Van Eek, 1995; Vlaeyen \& Linton, 2012). In contrast to a recent study showing a hyperalgesic effect of induced negative mood in migraine patients explained by pain catastrophizing (Goli, Asghari, \& Moradi, 2016), our findings corroborate with previous experiments that show pain catastrophizing (either at baseline or experimentally induced) 
does not seem to significantly affect pain responses in pain-free adults (Campbell, Quartana, Buenaver, Haythornthwaite, \& Edwards, 2010; Dixon, Thorn, \& Ward, 2004; Severeijns, van den Hout, \& Vlaeyen, 2005).

\section{Study Limitations}

Evaluating mental defeat's causal effects is inherently difficult due to understandable ethical concerns and the lack of established defeat induction procedures. We used the activation of mental defeat in pain-free adults as a cautious starting point, but it also meant that the findings of this study might not necessarily be extended to clinical samples. Further, the experimental pain induction which took place in this study incurs a lack of ecological validity - as painful sensations generated by the CPT may have limited application outside experimental pain. There is a predictability in experimental pain that is not shared by clinical pain (Bialosky, Hirsh, Robinson, \& George, 2008). The threat value and meaning carried by the experimental pain in this study is qualitatively different, in that participants were explicitly assured that there should be no lasting resultant noxious effects and that they could stop the procedure anytime, which is typically not possible with clinical pain. Due to these differences and the potential lack of statistical power in our analyses, it is essential for future studies to evaluate the causal effect of mental defeat on mood and pain responses in a larger clinical pain sample, using more ecologically valid tasks. From the results of the current pilot, we do not know the duration of the observed effects after the thought manipulation, and as such it is recommended any future replications involve a follow-up to observe such effects. Furthermore, given mental defeat's role in anxiety and depression, as well as their comorbidities in chronic pain conditions, it would be pertinent to consider their influence along with other plausible covariates in future studies. Finally, although the mental victory thought manipulation was used to offset the effect of activating defeat, its impact on outcome measures was not assessed. Considering past mood induction studies' findings and the reduction of defeat following the neutral memory recall, future replications should include a mental victory condition and examine whether reliving memories of personal triumph over pain could have mood-lifting and pain-relieving effects.

\section{Conclusions}

In sum, this study is the first to explore the effects of mental defeat on the immediate perception of pain in a pain-free population. Although we did not observe significant changes to measured pain outcomes, we did observe significant changes to ratings of mental defeat, mood and attention. Thus, future research may explore mood as a potential pathway through which mental defeat operates as well as attentional mechanisms in larger pain-free and, most importantly, chronic pain samples. This will help gain a more thorough understanding of the response variation in chronic pain conditions.

Acknowledgments The authors would like to thank Natasha Kwok and Sarina Afzalishamsabad for their help in the data collection and the participants for taking part in this study.

Funding This is a pilot study of research supported by Medical Research Council (MRC) grant MR/S026185/1 to NKYT. VC was funded by the University of Warwick Departmental PhD Fellowship, under the supervision of NKYT. The funders have no role in study design, data collection and analysis, decision to publish, or preparation of this manuscript.

Data Availability The datasets generated during and/or analyzed during the current study are available from the corresponding author on reasonable request.

\section{Declarations}

Financial Interests The authors declare they have no financial interests.

Ethical Approval This study was performed in line with the principles of the Declaration of Helsinki. Approval was granted by the University of Warwick's Humanities and Social Sciences Research Ethics Committee (HSSREC). This research study involving human participants was in accordance with the ethical standards of the institutional and national research committee and with the 1964 Helsinki Declaration and its later amendments or comparable ethical standards. The Humanities \& Social Sciences Research Ethics Committee (HSSREC) of the University of Warwick approved this study.

Informed Consent Informed consent was obtained from all individual participants included in the study.

Conflict of Interest On behalf of all authors, the corresponding author states that there is no conflict of interest.

Open Access This article is licensed under a Creative Commons Attribution 4.0 International License, which permits use, sharing, adaptation, distribution and reproduction in any medium or format, as long as you give appropriate credit to the original author(s) and the source, provide a link to the Creative Commons licence, and indicate if changes were made. The images or other third party material in this article are included in the article's Creative Commons licence, unless indicated otherwise in a credit line to the material. If material is not included in the article's Creative Commons licence and your intended use is not permitted by statutory regulation or exceeds the permitted use, you will need to obtain permission directly from the copyright holder. To view a copy of this licence, visit http://creativecommons.org/licenses/by/4.0/.

\section{References}

Amris, K., \& Williams, A. (2007). Chronic pain in survivors of torture. Pain: Clinical Updates, 15(7), 1-4.

Andre, J., Zeau, B., Pohl, M., Cesselin, F., Benoliel, J.-J., \& Becker, C. (2005). Involvement of cholecystokininergic systems in anxiety- 
induced hyperalgesia in male rats: Behavioral and biochemical studies. Journal of Neuroscience, 25(35), 7896-7904.

Arnow, B. A., Hunkeler, E. M., Blasey, C. M., Lee, J., Constantino, M. J., Fireman, B., Kraemer, H. C., Dea, R., Robinson, R., \& Hayward, C. (2006). Comorbid depression, chronic pain, and disability in primary care. Psychosomatic Medicine, 68(2), 262-268.

Asmundson, G. J., Norton, G. R., Allerdings, M. D., Norton, P. J., \& Larsen, D. K. (1998). Posttraumatic stress disorder and work-related injury. Journal of Anxiety Disorders, 12(1), 57-69.

Baas, M., De Dreu, C. K., \& Nijstad, B. A. (2008). A meta-analysis of 25 years of mood-creativity research: Hedonic tone, activation, or regulatory focus? Psychological Bulletin, 134(6), 779.

Bair, M. J., Robinson, R. L., Katon, W., \& Kroenke, K. (2003). Depression and pain comorbidity: A literature review. Archives of Internal Medicine, 163(20), 2433-2445.

Banks, S. M., \& Kerns, R. D. (1996). Explaining high rates of depression in chronic pain: A diathesis-stress framework. Psychological Bulletin, 119(1), 95-110.

Bialosky, J. E., Hirsh, A. T., Robinson, M. E., \& George, S. Z. (2008). Manipulation of pain catastrophizing: An experimental study of healthy participants. Journal of Pain Research, 1, 35.

Bjellend, I., Dahl, A. A., Huag, T. T., \& Neckelmann, D. (2002). The validity of the Hospital Anxiety and Depression Scale: an updated literature review. Journal of Psychosomatic Research, 52(2), 69-77.

Blackburn-Munro, G. (2004). Hypothalamo-pituitary-adrenal axis dysfunction as a contributory factor to chronic pain and depression. Current Pain and Headache Reports, 8(2), 116-124.

Brown, G. K. (1990). A causal analysis of chronic pain and depression. Journal of Abnormal Psychology, 99(2), 127-137.

Buhrman, M., Syk, M., Burvall, O., Hartig, T., Gordh, T., \& Andersson, G. (2015). Individualized guided internet-delivered cognitive-behavior therapy for chronic pain patients with comorbid depression and anxiety. The Clinical Journal of Pain, 31(6), 504-516.

Campbell, C. M., Quartana, P. J., Buenaver, L. F., Haythornthwaite, J. A., \& Edwards, R. R. (2010). Changes in situation-specific pain catastrophizing precede changes in pain report during capsaicin pain: A cross-lagged panel analysis among healthy, pain-free participants. The Journal of Pain, 11(9), 876-884.

Carnes, D., Taylor, S. J., Homer, K., Eldridge, S., Bremner, S., Pincus, T., Rahman, A., \& Underwood, M. (2013). Effectiveness and costeffectiveness of a novel, group self-management course for adults with chronic musculoskeletal pain: Study protocol for a multicentre, randomised controlled trial (COPERS). BMJ Open, 3(1), e002492.

Cleeland, C., \& Ryan, K. (1994). Pain assessment: Global use of the brief pain inventory. Singapore: Annals, Academy of Medicine.

Cohen, J. (1988). Statistical power analysis for the behavioral sciences (2nd ed.). New York: Psychology Press.

Cohen, J. (1992). Statistical power analysis. Current Directions in Psychological Science, 1(3), 98-101.

Denmark, A., Tien, D., Wong, K., Chung, A., Cachat, J., Goodspeed, J., Grimes, C., Elegante, M., Suciu, C., \& Elkhayat, S. (2010). The effects of chronic social defeat stress on mouse self-grooming behavior and its patterning. Behavioural Brain Research, 208(2), 553559

Dixon, K. E., Thorn, B. E., \& Ward, L. C. (2004). An evaluation of sex differences in psychological and physiological responses to experimentally-induced pain: A path analytic description. Pain, 112(1-2), 188-196.

Dunmore, E., Clark, D. M., \& Ehlers, A. (2001). A prospective investigation of the role of cognitive factors in persistent posttraumatic stress disorder (PTSD) after physical or sexual assault. Behaviour Research and Therapy, 39(9), 1063-1084.

Ehlers, A., Clark, D. M., Dunmore, E., Jaycox, L., Meadows, E., \& Foa, E. B. (1998). Predicting response to exposure treatment in PTSD: The role of mental defeat and alienation. Journal of Traumatic
Stress: Official Publication of The International Society for Traumatic Stress Studies, 11(3), 457-471.

Ehlers, A., Maercker, A., \& Boos, A. (2000). Posttraumatic stress disorder following political imprisonment: The role of mental defeat, alienation, and perceived permanent change. Journal of Abnormal Psychology, 109(1), 45-55.

Fishbain, D. A., Cutler, R., Rosomoff, H. L., \& Rosomoff, R. S. (1997). Chronic pain-associated depression: Antecedent or consequence of chronic pain? A review. The Clinical Journal of Pain, 13(2), 116137.

Fishbain, D. A., Lewis, J. E., \& Gao, J. (2014). The pain suicidality association: A narrative review. Pain Medicine, 15(11), 1835-1849.

Galambos, A., Szabó, E., Nagy, Z., Édes, A. E., Kocsel, N., Juhász, G., \& Kökönyei, G. (2019). A systematic review of structural and functional MRI studies on pain catastrophizing. Journal of Pain Research, 12, 1155.

García-Campayo, J., Rodero, B., del Hoyo, Y. L., Luciano, J., Alda, M., \& Gili, M. (2010). Validation of a Spanish language version of the pain self-perception scale in patients with fibromyalgia. $B M C$ Musculoskeletal Disorders, 11(1), 255.

Gilbert, P., \& Allan, S. (1998). The role of defeat and entrapment (arrested flight) in depression: An exploration of an evolutionary view. Psychological Medicine, 28(3), 585-598.

Goli, Z., Asghari, A., \& Moradi, A. (2016). Effects of mood induction on the pain responses in patients with migraine and the role of pain catastrophizing. Clinical Psychology \& Psychotherapy, 23(1), 6676.

Hazeldine-Baker, C. E., Salkovskis, P. M., Osborn, M., \& GauntlettGilbert, J. (2018). Understanding the link between feelings of mental defeat, self-efficacy and the experience of chronic pain. British Journal of Pain, 12(2), 87-94.

Johnson, J., Gooding, P. A., Wood, A. M., \& Tarrier, N. (2010). Resilience as positive coping appraisals: Testing the schematic appraisals model of suicide (SAMS). Behaviour Research and Therapy, 48(3), 179-186.

Keeney, A., Jessop, D., Harbuz, M., Marsden, C., Hogg, S., \& Blackburn-Munro, R. (2006). Differential effects of acute and chronic social defeat stress on hypothalamic-pituitary-adrenal axis function and hippocampal serotonin release in mice. Journal of Neuroendocrinology, 18(5), 330-338.

Kinsey, S. G., Bailey, M. T., Sheridan, J. F., Padgett, D. A., \& Avitsur, R. (2007). Repeated social defeat causes increased anxiety-like behavior and alters splenocyte function in $\mathrm{C} 57 \mathrm{BL} / 6$ and $\mathrm{CD}-1$ mice. Brain, Behavior, and Immunity, 21(4), 458-466.

Legrain, V., Van Damme, S., Eccleston, C., Davis, K. D., Seminowicz, D. A., \& Crombez, G. (2009). A neurocognitive model of attention to pain: Behavioral and neuroimaging evidence. Pain, 144(3), 230 232.

Linton, S. J., Nicholas, M. K., MacDonald, S., Boersma, K., Bergbom, S., Maher, C., \& Refshauge, K. (2011). The role of depression and catastrophizing in musculoskeletal pain. European Journal of Pain, 15(4), 416-422.

Loeser, J. D., \& Treede, R.-D. (2008). The Kyoto protocol of IASP basic

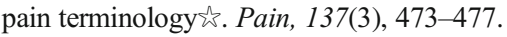

Marcinkiewcz, C. A., Green, M. K., Devine, D. P., Duarte, P., Vierck, C. J., \& Yezierski, R. P. (2009). Social defeat stress potentiates thermal sensitivity in operant models of pain processing. Brain Research, $1251,112-120$.

Martin, M. (1990). On the induction of mood. Clinical Psychology Review, 10(6), 669-697.

McNeish, D. (2017). Missing data methods for arbitrary missingness with small samples. Journal of Applied Statistics, 44(1), 24-39.

O'Connor, R. C., \& Nock, M. K. (2014). The psychology of suicidal behaviour. The Lancet Psychiatry, 1(1), 73-85. 
Pincus, T., \& Morley, S. (2001). Cognitive-processing bias in chronic pain: A review and integration. Psychological Bulletin, 127(5), 599-617.

Pompili, M., Innamorati, M., Lamis, D. A., Erbuto, D., Venturini, P., Ricci, F., Serafini, G., Amore, M., \& Girardi, P. (2014). The associations among childhood maltreatment, "male depression" and suicide risk in psychiatric patients. Psychiatry Research, 220(1-2), 571-578.

Price, J., Sloman, L., Gardner, R., Gilbert, P., \& Rohde, P. (1994). The social competition hypothesis of depression. The British Journal of Psychiatry, 164(3), 309-315.

Romano, J. M., \& Turner, J. A. (1985). Chronic pain and depression: Does the evidence support a relationship? Psychological Bulletin, 97(1), 18-34.

Serafini, G., Gonda, X., Canepa, G., Pompili, M., Rihmer, Z., Amore, M., \& Engel-Yeger, B. (2017). Extreme sensory processing patterns show a complex association with depression, and impulsivity, alexithymia, and hopelessness. Journal of Affective Disorders, 210, 249-257.

Severeijns, R., van den Hout, M. A., \& Vlaeyen, J. W. (2005). The causal status of pain catastrophizing: An experimental test with healthy participants. European Journal of Pain, 9(3), 257-265.

Sullivan, M. J., Adams, H., \& Sullivan, M. E. (2004). Communicative dimensions of pain catastrophizing: Social cueing effects on pain behaviour and coping. Pain, 107(3), 220-226.

Sullivan, M. J., Bishop, S. R., \& Pivik, J. (1995). The pain catastrophizing scale: Development and validation. Psychological Assessment, 7(4), 524-532.

Sullivan, M. J., Thorn, B., Haythornthwaite, J. A., Keefe, F., Martin, M., Bradley, L. A., \& Lefebvre, J. C. (2001). Theoretical perspectives on the relation between catastrophizing and pain. The Clinical Journal of Pain, 17(1), 52-64.

Tang, N. K., \& Crane, C. (2006). Suicidality in chronic pain: A review of the prevalence, risk factors and psychological links. Psychological Medicine, 36(5), 575-586.

Tang, N. K., Goodchild, C. E., Hester, J., \& Salkovskis, P. M. (2010). Mental defeat is linked to interference, distress and disability in chronic pain. Pain, 149(3), 547-554.

Tang, N. K., Salkovskis, P. M., \& Hanna, M. (2007). Mental defeat in chronic pain: Initial exploration of the concept. The Clinical Journal of Pain, 23(3), 222-232.
Tang, N. K., Shum, S.-H., Leung, P. W., Chen, P.-P., \& Salkovskis, P. M. (2013). Mental defeat predicts distress and disability in Hong Kong Chinese with chronic pain. The Clinical Journal of Pain, 29(9), 830-836.

Taylor, P. J., Gooding, P., Wood, A. M., \& Tarrier, N. (2011). The role of defeat and entrapment in depression, anxiety, and suicide. Psychological Bulletin, 137(3), 391-420.

Van Damme, S., Crombez, G., \& Eccleston, C. (2004). Disengagement from pain: The role of catastrophic thinking about pain. Pain, 107(1-2), 70-76.

Vlaeyen, J. W., Kole-Snijders, A. M., Boeren, R. G., \& Van Eek, H. (1995). Fear of movement/(re) injury in chronic low back pain and its relation to behavioral performance. Pain, 62(3), 363-372.

Vlaeyen, J. W., \& Linton, S. J. (2012). Fear-avoidance model of chronic musculoskeletal pain: 12 years on. Pain, 153(6), 1144-1147.

von Baeyer, C. L., Piira, T., Chambers, C. T., Trapanotto, M., \& Zeltzer, L. K. (2005). Guidelines for the cold pressor task as an experimental pain stimulus for use with children. The Journal of Pain, 6(4), 218 227.

Von Korff, M., \& Simon, G. (1996). The relationship between pain and depression. The British Journal of Psychiatry, 168(S30), 101-108.

Watson, D., Clark, L. A., \& Tellegen, A. (1988). Development and validation of brief measures of positive and negative affect: The PANAS scales. Journal of Personality and Social Psychology, 54(6), 1063-1070.

Wheeler, C. H., Williams, A. C. D. C., \& Morley, S. J. (2019). Metaanalysis of the psychometric properties of the Pain Catastrophizing Scale and associations with participant characteristics. Pain, 160(9), 1946-1953.

Williams, J. (2001). The cry of pain. Penguin.

Williams, J. M. G., \& Pollock, L. R. (2001). Psychological aspects of the suicidal process. Understanding Suicidal Behaviour, 76-93.

Zigmond, A. S., \& Snaith, R. P. (1983). The hospital anxiety and depression scale. Acta Psychiatrica Scandinavica, 67(6), 361-370.

Zigmond, A. S., \& Snaith, R. P. (1994). The HADS: hospital anxiety and depression scale. Windsor: NFER Nelson.

Publisher's Note Springer Nature remains neutral with regard to jurisdictional claims in published maps and institutional affiliations. 